\title{
The role of bladder neck repairs in the management of urinary incontinence in spina bifida patients Santosh Karmarkar* and Madhavi Thakur
}

\author{
Address: 111 A, Aradhana, G D Ambekar Marg, Dadar East, Mumbai 400014, India \\ Email: Santosh Karmarkar* - santoshjk@yahoo.com \\ * Corresponding author
}

\author{
from 50th Annual Meeting of the Society for Research into Hydrocephalus and Spina Bifida \\ Cambridge, UK. 30 August - 2 September 2006 \\ Published: 2I December 2006 \\ Cerebrospinal Fluid Research 2006, 3(SuppI I):S26 doi:I0.II86/1743-8454-3-SI-S26
}

(C) 2006 Karmarkar and Thakur; licensee BioMed Central Ltd.

\section{Background}

To analyse the role of bladder neck repairs (BNRs) in the management of urinary incontinence in spina bifida patients and to compare the results of the various techniques done by us.

\section{Materials and methods}

10 patients of spina bifida with urinary incontinence who underwent bladder neck tightening procedures as a part of their incontinence management were included in this retrospective analysis. These included 4 -Young Dee Leadbetter (YDL), 3-Slings, 2 Submucosal injections (SM), 1 Kropps procedure. The mean postoperative follow-up period was 3 years.

Results of these procedures were assessed with respect to technical difficulty, complications, predictability, ease of post-op catheterizations, postoperative improvement in leak-point pressures and their synergy with other adjuvant surgical procedures such as augmentations and stomas.

\section{Results}

Of the 4 YDL repairs 2 failed completely and did not improve the resistance at all. In 1 case the increase in resistance was very high and in one it was optimal. In all the 3 sling cases there was very good response in the short term (up to 1-2 years post-operatively) but later they were back to their original leak point pressures. There was also a complication of sling erosion in one case. The 2 SM injections were technically difficult and even on the table we could not appreciate any significant decrease in the size of bladder neck opening. The Kropps procedure was considered a failure because it resulted in a non-catheterisable bladder.

\section{Conclusion}

Most BNRs are not very useful procedures in the management of Urinary incontinence in SB. They should certainly not be done in isolation. The technical aspects, results and pro and cons of each type of procedure are discussed. 